\title{
REGENERACIONISMO Y COSTUMBRISMO: LOS NUEVOS ESPAÑOLES PINTADOS POR SÍ MISMOS DEL SEMANARIO ESPAÑA
}

\author{
ISABEL ROMÁN ROMÁN \\ isaroman@unex.es \\ Universidad de Extremadura
}

\section{Resumen}

Se analiza en este artículo la colección costumbrista de Los españoles pintados por sí mismos que el semanario novecentista España fundado por Ortega y Gasset ofreció a lo largo de su primer año de existencia, 1915. El análisis de los veintidós nuevos tipos de españoles pintados por veintiún prestigiosos escritores, los pone en relación con las ideas regeneracionistas aparecidas en numerosos artículos de la revista Alma española en los años 1903 y 1904.

Palabras clave: Colección costumbrista, regeneracionismo, novecentismo, revista Alma española, semanario España, Ortega y Gasset.

\begin{abstract}
This article analyses the costumbrista collection Los españoles pintados por sí mismos that España, the weekly noucentista newspaper founded by Ortega y Gasset published during its first year of existence, 1915. The analysis of twenty-two new types of Spaniards painted by twenty-one prestigious writers, put them in relation to the ideas of Regenerationism appeared in numerous articles of Alma española magazine in the years 1903 and 1904.
\end{abstract}

Keywords: Collection of costumbrista articles, Regenerationism, Noucentisme, Alma española magazine, España newspaper, Ortega y Gasset.

Anales, 26, 2014, pp. 421-449 
El carácter regeneracionista, intelectual y reformista de la revista España (que incluye como redactores a Ortega y Gasset, Pío Baroja, Ramiro de Maeztu, Ramón Pérez de Ayala, Luis de Zuluaga, Eugenio D’Ors o Gregorio Martínez Sierra) se declaraba ya en el número inaugural del 29 de enero de 1915. En «España saluda al lector» advierten los editores que desde 1898 venían observando atentamente «el desenvolvimiento de la vida española», con el resultado de recibir cada día de esos diecisiete años «impresiones ingratas. Cuanto más patriotas éramos, mayor enojo sentíamos». La terminología regeneracionista sobre los males de la patria se hace presente desde este primer número, cuando anuncian que en el siguiente iniciarán una serie de artículos titulada «El Banco de España, plaga nacional», muy expresiva en su diagnóstico de uno de los males del país, en la línea alegórica tan frecuente en la sociología, el pensamiento y la literatura regeneracionistas desde el fin de siglo, asunto del que me ocupé en otro lugar. (Román Román, 2000).

Una de las sorpresas que contuvo la revista España fue el proyecto de continuar en 1915 la colección costumbrista de Los españoles pintados por sí mismos que se había editado en dos volúmenes entre 1843 y 1844 . En el n. ${ }^{\circ}$ 3 de la revista, el 12 de febrero, comenzaba a insertarse semanalmente la publicidad del proyecto de una nueva serie costumbrista, insistiendo en un carácter «pintoresco» que a priori tenía escasa conexión con el designio crítico y modernizador del proyecto editorial de la revista, y con el propio contexto de la guerra europea que ocupa asiduamente a sus colaboradores: «En breve comenzaremos la publicación de esta serie de estudios pintorescos dedicados a la vida nacional, renovando así la famosa obra compuesta en colaboración por los escritores de 1840», declaraban.

Veintidós nuevos tipos de españoles (dieciocho masculinos y cuatro femeninos), pintados por veintiún escritores ya prestigiosos a la sazón, vendrían a dotar de amenidad literaria a una o dos páginas, usualmente las numeradas como 7 y 8 , de las doce que contenía cada número del semanario en $1915^{1}$. Los veintiún autores que firmaron los artículos de la nueva serie pertenecen por su edad a dos generaciones como mínimo: desde el mayor, Antonio Zozaya, nacido en 1859, hasta los nacidos en la década de los sesenta (Santiago Rusiñol, Joaquín Dicenta, José Francos Rodríguez, Francisco Acebal, Eduardo

1. Debido a la gran cantidad de citas que en adelante aparecerán sobre los artículos de la serie en el semanario España, solo indicaremos las páginas cuando no correspondan a las habituales 7 y 8 en las que se ubicaban los artículos. Puede consultarse la vida completa de la publicación en su edición digitalizada en la Hemeroteca Digital de la Biblioteca Nacional de España, e igualmente en la edición facsimilar que figura en la Bibliografía final, donde también se anota la edición facsimilar de Alma española. 
Gómez de Baquero Andrenio), los nacidos en la década de los setenta (los hermanos Álvarez Quintero, Manuel Bueno, Luis Bello, Enrique Díez Canedo, Gabriel Miró, Rafael López de Haro), en los ochenta (Emilio Carrere, Pedro de Répide, Antonio Hoyos y Vinent, Andrés González Blanco, Eugenio Noel), hasta los más jóvenes Cipriano Rivas Cheriff, Joaquín Montaner y Luis Fernández Ardavín, que en las fechas de su aportación a la colección costumbrista contaban menos de veinticuatro años.

La nueva serie de Los españoles pintados por sí mismos, comenzada en el n. ${ }^{\circ} 20$ de 1915, no prosiguió en 1916, pese a que el número con el que se cerraba 1915 (n. ${ }^{\circ} 49$ de la publicación, de 30 de diciembre) anunciaba que las novedades del año entrante alternarían con secciones ya asentadas, como era a la sazón la de la serie costumbrista. Pese a ello, la colección concluyó con el primer año de la revista y, a lo sumo, el éxito que habían tenido los artículos se aprovechó como acicate publicitario para anunciar nuevas obras de los autores. Así vemos que en el número de 13 de enero de 1916, p. 20, en la publicidad de la nueva obra de Eugenio Noel Nervios de la raza se apelaba al éxito de los que llamaban «estudios» de Noel, único autor que redactó dos artículos para la serie costumbrista.

\section{La colección de «Los españoles pintados por sí mismos», cuerpo extraño en el contexto de la información sobre la guerra en 1915}

Como era de esperar dadas las circunstancias bélicas, el editorial titulado «España a sus lectores» en el n..$^{\circ} 18$ de 28 de mayo, cerca ya de cumplirse el primer semestre de vida de la revista, declaraba la dificultad de combinar «el tono de seriedad y amargura impuesto por la gran tragedia y aquellas notas variadas y múltiples que necesita la amenidad».

En un entorno de permanente preocupación y seguimiento de la guerra, una parte destacada de cada número del semanario en 1915 la constituía la sección «Últimos hechos importantes de la guerra» en sus distintos frentes, y se completaba con ocasionales artículos de ilustres colaboradores que defendían posturas aliadófilas y ponían en cuestión la neutralidad decidida por el gobierno español. Así, el 11 de junio Luis Araquistáin y Ramiro de Maeztu proclaman la necesidad de solidaridad en la guerra, Unamuno escribe en «El porqué de la crisis» el 2 de julio contra el aislamiento y la neutralidad del gobierno Dato frente a la guerra, argumentando la necesidad de ayudar a los aliados, mientras que Ortega y Gasset, fundador y alma mater de la revista, redacta a menudo sus reflexiones sobre este asunto.

En el número del 9 de julio ocupa lugar predominante el «Manifiesto de adhesión a las naciones aliadas» firmado por Gumersindo de Azcárate, 
Américo Castro, Julio Cejador, Manuel B. Cossío, Marañón, Ortega, Unamuno, Menéndez Pidal, Azaña, Azorín, A. Machado, Maeztu, Galdós, Palacio Valdés, Pérez de Ayala, Valle Inclán, Luis Simarro y pintores como Ramón Casas, Santiago Rusiñol e Ignacio de Zuloaga, entre otros, manifiesto que según el editor se redactó en francés y se dio a difundir primero en la prensa extranjera, siendo esta la primera vez que aparecía en español.

Se anuncia reiteradamente una Historia ilustrada de la Guerra de 1914 a cargo de Gabriel Hanotaux, exministro francés, en cuatro volúmenes en cuadernos quincenales, con traducción de Luis Ruiz Contreras y prólogo de Unamuno. Abundantes fotos en casi todos los números, ilustran las consecuencias de la guerra, y muchas de las portadas gráficas de la revista, sobre todo las realizadas por el gran caricaturista Bagaría, reflejan críticamente aspectos de la contienda. Por ejemplo la portada del n. ${ }^{\circ} 31$, el 26 de agosto representa a dos damas que sostienen esta conversación:

-Dicen que las guerras vigorizan los pueblos.

-Claro, cuando quedan pueblos después de las guerras.

En la portada de Bagaría del 2 de septiembre, el diálogo de los dos niños dibujados es igualmente expresivo:

- ¿Qué eres tú, francófilo o germanófilo?

$-i$ Yo? ...¡Huérfanofobo!

El propio Bagaría mantuvo además una tira de viñetas denunciadora de la ocupación alemana, serializada a lo largo de varios números, con el título «El profesor Herr Mayer y la expansión germánica».

Con todas las precauciones, y advirtiendo que no quisieran caer en la disonancia de los tonos antes mencionados, los editores de la publicación presentaron en tal escenario tres nuevas secciones literarias, una de las cuales era la colección Los españoles pintados por sí mismos, que se proponía dar «los tipos más característicos de nuestra tierra y de nuestro momento, a cargo de los más renombrados escritores». En este peculiar contexto se ofrecía la aportación literaria de la nueva serie de artículos de costumbres, cada cual con su ilustración, como en la colección del siglo XIX.

\section{La reflexión contemporánea sobre el «alma española» y las «almas regionales»}

La convicción regeneracionista de la existencia de un «alma española» que era preciso conocer para efectuar debidamente el diagnóstico y curación de los males nacionales, era muy evidente desde principios de siglo en publicaciones periódicas, artículos y libros cuyos marbetes y títulos actuaban ya 
como declaración de principios. Recordemos como ejemplos los textos de $E l$ alma castellana, publicados por Azorín en 1900, o la recopilación de ensayos de Rafael Altamira editada en 1902 con el título Psicología del pueblo español. Por su parte, la revista Alma española desglosó en algunos de sus 23 números desde noviembre de 1903 a abril de 1904 las supuestas particularidades regionales, con su inclusión en ella de la conocida serie sobre las «almas regionales». La tendencia de la época al estudio de las psicologías sociales se hace muy presente en artículos como el de Francisco Acebal, cuya «Alma asturiana» apareció el 3 de enero de 1904 en pp. 2-4, advirtiendo contra la tendencia castellano-céntrica que tanto perjudicaba al conocimiento de otras regiones, y contra el hecho de que «todo estudio de psicología española» había acabado por ser «estudio de psicología castellana».

Este tipo de artículos obtuvo un lugar predominante en la revista hasta llegar a ocupar las primeras páginas de sus números correspondientes: es el caso de Miguel Santos Oliver y su «Alma mallorquina» el 29 de noviembre de 1903, o el «Alma andaluza» de José Nogales, que abría el número 5 de Alma Española el 6 diciembre del mismo año, advirtiendo su autor que no quería pintar una pandereta, sino ofrecer «una instantánea» de la Andalucía actual, para lo cual tenía que tratar la apatía de los terratenientes y la consideración del jornalero como «un apero de labranza a la entera disposición del señor de la tierra». Dada la extensión de Andalucía, hubo un desglose particular, el titulado «Alma granadina» publicado por Rodrigo de Acuña el 7 de febrero de 1904. Por su parte, Antonio Royo Villanova abrió con su «Alma aragonesa» el número de Alma española de 21 de febrero de 1904. Joan Maragall publicaba su «Alma catalana» el 24 de enero de 1904, y en la semana siguiente, Manuel Feliú escribía sobre el «Alma riojana», el 31 de enero.

Algunos de los que colaboraron en Alma española con aportaciones al conocimiento de las almas regionales, fueron elegidos para contribuir también con sus artículos en la serie de Los españoles pintados por sí mismos que la revista España decidió ofrecer en 1915. Pervivirá en el semanario España el planteamiento de las peculiaridades regionales, con especial atención a las catalanas ${ }^{2}$. «El viajante catalán», publicado por Santiago Rusiñol en el n. ${ }^{\circ} 20$

2. La relación de Cataluña con el resto de España dio lugar a decenas de artículos, en la línea del publicado el 29 de julio, «Conferencias en Barcelona. El pensamiento catalán ante el conflicto europeo», sobre un ciclo de conferencias de parlamentarios catalanes editado luego en libro. Del tono reivindicativo general da idea el artículo «Cataluña como látigo» publicado el 18 de enero dentro de la sección «La vida real de España», que contiene una defensa de cómo Cataluña se venía enfrentando al Parlamento desde el comienzo de la guerra en 1914, con el fin de combatir «reciamente contra las plagas de la economía española». Si recurrentes eran en España las páginas dedicadas a revisar 
de España, el 11 de junio, es el artículo que representa en la colección este interés por la cuestión catalana. El autor no elude plantear el candente asunto del «alma catalana» y su relación con el resto de España, si bien trata de forma desenfadada las pretensiones diferenciadoras del catalán. El viajante que da título al artículo exhibe un espíritu orgullosamente nacionalista, refrendado con citas de dos figuras esenciales del nacionalismo, como Pi i Margall y Prat de la Riba. La exageración del tipo, que llega a augurar la invasión de productos catalanes por todos los continentes, adquiere un calculado efecto cómico. Como el viajante se desplaza por tantas regiones de España, no faltan los amagos de discusión con las «fuerzas vivas» locales de provincias, con los que Rusiñol formula en tono menor el problema del conflicto de intereses entre las distintas regiones, asunto que aparece abordado en forma humorística. El problema del uso de su lengua materna entre los viajantes catalanes cuando coinciden en diversos puntos de España ocasiona trifulcas con otros españoles, que concluyen siempre amigablemente. No es menos importante destacar la sutil crítica al anquilosamiento provinciano español que contiene el artículo. Ciertos apuntes sobre las vidas provincianas y la revolución que causa en ellas la llegada del viajante, le bastan al autor para bosquejar escenas muy vivas sobre la vida de las mujeres provincianas inmersas en el quiero y no puedo y en la cursilería a la que se veían obligadas por las apariencias sociales. Esas

pobres moscas, hijas de empleados de poco sueldo, de subdelegados, de sabe Dios qué, a las pobres capitanas [...] las secretarias de ayuntamiento con más esperanzas que dinero, pobres flores marchitas de rambla provinciana que no tiene más visión que las acacias de la plaza

nos recuerdan las figuras que, encarnadas en personajes, aparecieron en obras de Clarín, Pardo Bazán o Galdós³ .

el estado de la enseñanza en el bachillerato y en la universidad, la llamada «cuestión catalana» se extendía igualmente a este asunto, para elogiar la autonomía local escolar y las ventajas de los sistemas propios de enseñanza. Por otra parte, la llamada cuestión de Cataluña dio lugar a series como «La vida real de España. Por Cataluña y por todos» que recoge las respuestas de intelectuales, diputados, economistas, etc. a una encuesta sobre la conveniencia o perjuicio para la economía catalana de implantar zonas neutrales en el litoral catalán, y muy relacionado con ello, sobre la autonomía y autogestión catalana en asuntos económicos.

3. La capacidad para el costumbrismo de Rusiñol queda bien demostrada, además de en este excelente artículo, en otras de sus colaboraciones de estirpe costumbrista en el semanario España, como las que suele incluir en su sección «Paradojas de un español». Por ejemplo, en el número del 25 de noviembre, el artículo «El inglés de las cosas viejas» enfoca el provincianismo español mediante los desplazamientos de un extranjero, el inglés viajero excéntrico, amigo de recorrer cada rincón, de curiosear entre muebles antiguos, con la consecuencia de que muchos pueblerinos adquieren tal orgullo por sus 
Por lo que respecta a Andalucía, «El fenómeno» de Eugenio Noel, último de la colección que estamos tratando, editado el 30 de diciembre, presenta un sorprendente inicio retórico en cursiva, con una especie de laudatio que contiene todos los tópicos del romanticismo idealizante sobre Andalucía, con el fin de contrastarlos con su «podredumbre» (sic) presente. En «El fenómeno» Noel justifica la necesidad de seres excepcionales que sirvan de referentes en cada nación y que contrarresten tantas pasiones y energías depositadas en lugares erróneos: «Un sabio creador, un artista prodigioso, el estadista perfecto, recogiendo empresas e iniciativas dispersas, forman una civilización, dan un rumbo, orientan, salvan». De nuevo el autor avisa de un riesgo: cuando pasan décadas sin que aparezca nadie capaz de «urdir» en el medio ambiente «una vigorosa renovación» el pueblo señala inadecuadamente a ciertos seres, que no merecen tal admiración. Noel intenta trascender la figura del «fenómeno» (el torero andaluz de éxito) de su artículo, para explicar cómo la psicología nacional y el espíritu de la Raza (sic) ibera tienen estrecha relación con la psicología del torero en la plaza y el espíritu y motivaciones del público que lo aclama.

El mismo autor, en la parte titulada «Andalucía trágica» en su artículo «El señorito chulo» publicado el 8 de noviembre, resume los supuestos rasgos negativos del pueblo andaluz como tal. Subyaciendo igualmente en el autor madrileño el concepto noventayochista de las peculiares «almas» de los pueblos, editorializa rotundamente sobre cómo «Al latifundio no opone [el pueblo andaluz] una sublevación de campesinos [...] Al cacique no sabe vencerle sino con su torero», e igualmente busca una explicación de psicología social a los comportamientos que ejemplifica su artículo: los andaluces idolatrarían a los toreros al identificarse con su ascenso social y su venganza

antiguallas carcomidas que antes morirían de hambre que venderlas. Otros tipos extranjeros de viaje por España que componen esta sección son «Las inglesas acuarelistas», el 26 de febrero, p. 3, donde con humor se presentan esas figuras tan extendidas de las inglesas que caen sobre España para levantar acta con su caballete y sus acuarelas de todas las ruinas del país. En la misma sección «Paradojas de un español», el 19 de marzo, pp. 2 y 3 , aborda en su parte segunda la vida ociosa centrada en el cante y en tomar el sol, de los gitanos del Sacromonte, cuya supuesta aversión al trabajo trata Rusiñol con su habitual humor. Por poner un último caso -de entre tantos posibles- de las habilidades del autor catalán para la tipificación costumbrista, mencionaremos ${ }_{i} \mathrm{O}$ h, lo pintoresco!», publicado el 14 de mayo, p. 5, donde ridiculiza una costumbre asociada a la expansión del turismo: cómo todo turista en Granada, sea español o extranjero, cree necesario disfrazarse de moro y hacerse la típica foto de souvenir en la ciudad andaluza. Además de pintarse escenas sobre esta situación, se elucubra con gracia sobre cuál será la causa de esta tendencia irresistible de sentirse moro fiero por un rato, y de dejar constancia de ello en una foto.

Anales, 26, 2014, pp. 421-449 
de la pobreza. Generaliza Noel caracterizando a los andaluces como impulsivos, acomodaticios, poco trabajadores, amigos del vino y la guitarra, y a los obreros andaluces como serviles respecto a los señoritos, lo que impide que sus vidas avancen.

No faltan tampoco en la nueva serie de Los españoles pintados por sí mismos las tradiciones consuetudinarias regionales (recordemos, respecto a Cantabria, el modelo de señor rural que plasmó Pereda en el señor de Provedaño de su Peñas arriba), aquí representadas en otra región por Fernández Ardavín en su artículo «El patriarca de Castilla», de 23 de diciembre, donde defiende la institución familiar del patriarcado como algo netamente castellano, y la contrapone a lo que considera la dispersión propia de astures, galaicos y levantinos.

\section{Las variedades formales de los artículos}

Los artículos de la serie, cuyos títulos remiten siempre a tipos y no a escenarios, ambientes o situaciones, son de extensión y estructura muy variables: desde un único texto (caso de «El cochero de punto», publicado el 9 de septiembre por Antonio Zozaya) hasta otros divididos en dos partes, tres e incluso cuatro, algunas tituladas, lo que daría más la impresión de un conjunto de viñetas o de un relato breve. Hay un único caso de texto en verso: «El hereu» de Joaquin Montaner, publicado el 25 de noviembre en p. 10, con 12 estrofas de ocho versos hexasílabos.

En cuanto a las formas constructivas, destacaremos algunas peculiares, mencionando en primer lugar las modalidades autobiográficas y la ficción autobiográfica, para referirnos luego a otros modelos, como el reportaje periodístico, el cuento o relato breve, la estampa, la carta ficticia, la tendencia teatral y la predominante descripción de ambientes.

En la primera modalidad, el médico José Francos Rodríguez, además de prestigioso periodista de éxito desde muy joven y luego político, publicó su artículo «El médico» el 16 de julio, proyectando su experiencia personal, aunque manteniendo la tercera persona y las generalizaciones propias del artículo costumbrista. Su experiencia es la «autoridad» que le permite distanciarse de los estereotipos que la tradición literaria, y en concreto el costumbrismo del siglo XIX, habían ido proyectando sobre un tipo que estaba presente también en Los españoles pintados por sí mismos de 1843, en el artículo de igual título firmado por el Licenciado José Calvo y Martín. Calvo proporcionaba datos históricos sobre el tipo, con un estilo festivo y hasta zumbón, que aplicaba también a novedades de la medicina de su tiempo como la homeopatía. Presentaba Calvo el recorrido de una vida prototípica de médico, desde la salida 
de la facultad, el primer destino como médico rural, la instalación en la capital, el ascenso progresivo en fama y calidad de la clientela, hasta el momento del feliz retiro y de la muerte. Por su parte, en el artículo de 1915, José Francos incluye informaciones precisas y contemporáneas sobre los estudios de Medicina y sus dificultades por la escasez de cadáveres para practicar, sobre los profesores de las facultades, sus sueldos y cómo deben compatibilizar la enseñanza con sus consultas particulares, y también acerca de sus visitas a las casas particulares. Detalles concretos como la información sobre los emolumentos de los médicos según su categoría prueban el conocimiento real y práctico del autor sobre el asunto, y también un tratamiento del tipo más ensayístico, y muy distante del espíritu humorístico del artículo homónimo del s. XIX.

«El notario», publicado por Rafael López de Haro el 2 de diciembre, es un caso semejante. El escritor opta por seleccionar como tipo algo que conoce muy bien, por tratarse de una profesión que desempeñó durante muchos años, paralelamente a su tarea como escritor y articulista. De su vida personal proceden las anécdotas sobre el primer destino rural en una notaría de tercera, los entresijos del escalafón, el ascenso a localidades mayores, etc. También las distintas escenas que aparecen en este artículo, cuyo inicio se separa de las convenciones del género, partiendo ya de la elección de la primera persona narrativa, y de la evidencia de que el notario-escritor del que empieza por hablar es el propio autor. No es preciso, pues, acudir a las citas ajenas ni a las autoridades que eran tan comunes en la colección del siglo XIX, ya que la propia experiencia del escritor es el mejor aval, y le permite incluso rebatir los estereotipos de grisura y rutina que puedan existir sobre la profesión. El autor dedica una segunda parte del texto, más técnica, a la situación del notariado español como institución, con lo que de nuevo se acerca a una modalidad de artículo de prensa de información.

Por último, la ficción autobiográfica con ecos del Siglo de Oro organiza el amplio artículo de Luis Fernández Ardavín «El patriarca de Castilla». Hasta avanzado el relato y como al desgaire, no sabremos de las características de la persona que narra, pues el autor juega a la mixtificación autobiográfica en varias ocasiones, desde el comentario que atribuye a los chicos del lugar, que le llamaban «el primo Luis», y más tarde «el que escribe en los papeles». Los datos biográficos de Ardavín no coinciden, pero se juega a añadir mayor realismo a la ficción del relato autobiográfico. Un escritor adulto de vida urbana, que finge ser el Luis que firma, reconstruye sus recuerdos de una infancia prototípica de pueblo, en medio de una numerosísima familia de la cual forma parte central el patriarca de Castilla que se pretende tipificar. 
Aparecen detalladas historias familiares, rematadas con conclusiones generales que elevan la anécdota a categoría, según lo requiere un artículo de costumbres.

La forma de reportaje periodístico es una opción innovadora por lo que respecta al género del artículo de costumbres, y es la adoptada por el artículo del 22 de septiembre «La estrella del género ínfimo», de Serafín y Joaquín Álvarez Quintero. La apócrifa andaluza Rafaelita Espejo inventada por ellos da nombre a un supuesto modelo vivo que va a servir para el retrato del tipo, organizado como una entrevista periodística de un también apócrifo escritor y periodista, Juan Martín, que se dispone a visitar a Rafaelita aprovechando que está en Madrid. El periodista se manifiesta decidido a «investigar su vida y costumbres, oír hablar de su arte, observar su curioso aposento...», en un interesante comentario metaliterario que a la vez da cuenta del modelo de artículo de costumbres que los Quintero desean redactar. La parte II del artículo deriva hacia lo teatral, al modo de un breve sainete muy en consonancia con las obras que dieron fama a los autores, con diálogos en dialecto andaluz por lo que atañe a una señora, «la agüela» que recibe al periodista. La entrevistada Rafaelita, como no podría ser de otro modo, es caracterizada como elocuente, pues el interés de su historia depende en buena medida de su propio relato. Finalmente, el lector ha compartido el proceso de creación del texto: la búsqueda del modelo vivo, la descripción empírica de la casa y entorno por parte del periodista testigo, y la reproducción directa de la palabra de la andaluza como fuente de toda la información.

Otra opción formal nos aproxima al cuento o relato breve que caricaturiza a un protagonista estudioso y ajeno al fluir de la vida de su tiempo, al modo del archivero y el científico del relato «Dos sabios» de Clarín. Nos referimos a «El erudito» de Gómez de Baquero, Andrenio, aparecido el 2 de septiembre. Se trata de un tipo universal, ni específicamente español ni contemporáneo, un figurón cuya conexión con el tipo literario del pedante es manifiesta. Convendrían perfectamente a este tipo las apreciaciones sobre la tendencia de algunos artículos costumbristas del siglo XIX a «deformar y caricaturizar al tipo estudiado, acumulando una serie de rasgos o incidentes» (Rubio Cremades y Ayala, p. 39).

La parte tercera y última del artículo contiene un ademán narrativo de escena prototípica que hemos visto en algunas novelas en las que aparece una fonda de estudiantes, como es el caso de El doctor Centeno galdosiano. Aquí también los estudiantes embroman al erudito que habita en la misma pensión, y que vive completamente fuera del mundo contemporáneo y real: le preguntan por Brest-Litovsk (en alusión a la batalla habida en esa ciudad 
por entonces rusa) y el erudito ignora el contexto bélico contemporáneo; cuando recibe aclaración, orgullosamente dice que a él la guerra «le importa un pito».

El animado diálogo de los jóvenes en esta parte cierra el texto con verdaderas greguerías puestas en boca de los ingeniosos estudiantes de Filosofía y Letras, que sintetizan mediante metáforas los juicios de valor que merece la inútil ocupación del erudito, su tarea de búsqueda de legajos insignificantes que sólo a él interesan.

El género de relato breve que el propio autor subtituló en ocasiones como «estampa» o «viñeta» está muy cerca de la modalidad de artículo a la que pertenece «El sepulturero» de Gabriel Miró, editado el 30 de septiembre ${ }^{4}$. Miró no se ciñe solo al tipo que enuncia el título, sino que traza estampas intemporales de la vida de un pueblo junto al mar. Su interés preferente por las escenas del lugar le condiciona a forzar la trabazón textual, para no perder de vista su compromiso de dibujar un tipo. Por ello selecciona, de entre la vida del pueblo, aspectos que obligadamente van a relacionarse con la muerte: la flor que lleva una joven en el cabello bien podría haber sido quitada por su padre de una sepultura; los niños que corretean, juegan y meriendan por los campos cercanos al pueblo, de repente regresan corriendo porque han visto «al hombre que no tiene miedo de los muertos». El día de los difuntos y las costumbres del lugar se seleccionan igualmente al hilo del tipo que da título al artículo, texto que pone de relieve el nexo invisible entre la vida -idílica, despreocupada, gozosa- y la muerte en la aldea. Miró opta por atrevidas analogías al modo del Larra de «El día de los difuntos», en su caso para vincular los cementerios reales que suelen estar en el exterior de las ciudades, con las oficinas que ocupan el centro de esas ciudades, y cuyos empleados son vistos como figurados sepultureros: «Es el sepulturero de las grandes metrópolis modernas. Oficinas municipales: los cadáveres son legajos, los sepultureros, ordenanzas».

Un apunte de relato de terror viene a converger en tan heterogéneo artículo: el sepulturero abre una fosa iy aparece flotando el muerto, que había sido sepultado un día de mucha lluvia! La evocación de la paz de la aldea, el paisaje y el detallismo sensorial tan característicos de Miró, aparecen en contrapunto permanente con los vislumbres de la muerte, tan estremecedores para casi todos, y tan naturales y rutinarios para una profesión en permanente contacto con ella.

4. Con texto casi idéntico, el artículo apareció recogido como «cuento» en Del vivir, Corpus y otros cuentos, Obras completas de Gabriel Miró, vol. I, Madrid, Biblioteca Nueva, 1927.

Anales, 26, 2014, pp. 421-449 
La carta ficticia es el molde escogido por C. Rivas Cheriff para «Un muchacho bien», publicado el 21 de noviembre. Un joven español que pasa su veraneo en Francia, envía una carta fechada en Biarritz en septiembre de 1915 (un mes antes de su publicación en el semanario España, por tanto), y comenta las incomodidades y cambios que le ocasiona la guerra en su vida de señorito en vacaciones. La carta se inserta en una estructura enmarcada, con una apertura de presentación y un cierre en los que aparece explícita la voz del escritor. El cierre es particularmente ingenioso, y vale por toda una explicación de por qué Rivas Cheriff ha resuelto el artículo mediante la opción epistolar, que hace innecesarios los juicios de valor explícitos y las descalificaciones que merece un tipo tan egocéntrico y ajeno al drama histórico de su tiempo: «Copio y concluyo: El estilo es el hombre», afirma el «editor» de la carta, interpretando a su modo la famosa propuesta de Buffon. Vale decir aquí que el dar voz propia a un individuo es suficiente para que se descubra así todo su ser.

«Morganáticas» de F. García Sánchez, publicado el 7 de octubre, muestra cierta tendencia teatral, y se organiza en dos viñetas entre las que media un lapso temporal de muchos años, los que separan la primera juventud de la madurez de la dama que representa al tipo. Una escena dialogal muestra cómo una dama madura pretende transmitir sus enseñanzas a una joven, e incitarla a aceptar la relación con un gran caballero. Luego se ofrece una escena de tertulia en el presente del relato, con tres caballeros en casa de la morganática ya madura en la que devino aquella joven que recibió las enseñanzas.

«El señorito chulo», pese a que se inicia in medias res de forma dialogal, con la expresión de dos personajes que se comunican en un dialecto andaluz, tiende a la escena y la descripción de ambientes. La segunda y tercera partes de este artículo largo y heterogéneo, dedicadas a las peleas de gallos, son de carácter descriptivo, y un verdadero estudio de ambiente: luces, olores, gestos y atavío de los asistentes, descripción de cada movimiento de los gallos en el llamado reñidero, lugar donde se encuentran tanto el obrero como el señorito, con el único vínculo de su pasión por las peleas de estas aves.

La retórica del artículo de costumbres: conexiones con la colección homónima del siglo XIX

Nos referimos en este punto a las imitaciones de estilemas acuñados por el género a lo largo del siglo XIX, y que los colaboradores de España demuestran conocer, a veces para imitarlos, y en otras ocasiones para distanciarse explícitamente de ellos. Entre estos estilemas imitados están: 
1. Las explicaciones lingüísticas

2. El recurso a las autoridades que se han ocupado anteriormente del tipo

3. La tradición costumbrista de explicar el origen y la evolución histórica del tipo

4. Las clasificaciones y subclasificaciones del tipo

5. Los dos paradigmas básicos del trazado biográfico y temporal de la vida del tipo: el seguimiento de un día o jornada en su vida a modo de ejemplo, o bien el resumen biográfico o recorrido por toda la vida del tipo hasta su muerte, al modo del artículo «La santurrona» de Antonio Flores en la colección Los españoles pintados por sí mismos del s. XIX, por citar sólo un ejemplo significativo.

1. Al igual que centenares de artículos costumbristas del siglo XIX dedicaban una sección, normalmente sus primeros párrafos, a la disquisición terminológica, buena parte de los artículos de la nueva colección definen el término que da nombre al tipo, e incluso explican su etimología. «La deportista» se atiene a esta convención costumbrista de comenzar explicando el vocablo, y ofrece un apunte lingüístico que rebosa humor e ironía sobre el moderno vocablo «deporte», al que dice preferir en su origen inglés, sport, así como referirse a la sportman para recordar que el tipo no es nacional, sino que proviene de Inglaterra y Estados Unidos. En «El opositor» el autor desplaza con humor la obligada "definición del vocablo» al centro del artículo, y además dota de otro sentido a la definición y etimología del término para acabar, tras el patrón del recorrido etimológico, remitiendo jocosamente a una de las autoridades: «(Véase Cicerón)».

Pedro de Répide afirma en «El golfo» que el uso de la denominación se ha ido desvirtuando, para resultar que el golfo es en el presente mucho más digno que el tipo contemporáneo de el señorito sinvergüenza, que "puede llegar a ser concejal, diputado provincial, padre de la Patria, director general, subsecretario».

En «Morganáticas» se explica pronto el sentido del vocablo, en su acepción de eufemismo contemporáneo que nunca recogería un diccionario académico, pero sí estos otros «diccionarios de autor» en que se convierten las propuestas de acepciones que cientos de artículos de costumbres nos proporcionan: «No se engañe nadie pensando que el vocablo morganáticas conserva aquí su legítimo sentido de esposa cuyo rango no alcanza al del marido. La cortesía y el ingenio aplican la palabra a las amantes de los grandes señores». Pueden notarse las conexiones con dos tipos anteriores, cuyas 
denominaciones habían sido también definidas por sus autores: el tipo de «La coqueta» pintada por Ramón de Navarrete en la primera colección de Los españoles pintados por sí mismos, sobre todo en la variedad «la coqueta de buen tono», que para Navarrete era «el tipo legítimo y verdadero, y el que me propongo describir» (Los españoles pintados por sí mismos, 1851, p. 38), y el tipo «La mujer del mundo» de Tomás Rodríguez Rubí en la misma serie.

«El fenómeno» de Noel perfila las definiciones burlonas del vocablo que da título al artículo: no se trata de recordar la definición lexicográfica de fenómeno, sino de proponer otra tomada del uso cotidiano. Juzga Noel que España solía buscar sus ídolos entre los luchadores y, en el siglo XIX, entre los militares. Pero al ver defraudadas sus expectativas, ha encontrado a su objeto de adoración en el torero de éxito, al que equivale el término «fenómeno» del título. A partir de la crítica lingüística del abuso del calificativo de «fenómenos» aplicado a los militares en el siglo XIX y a los toreros en el inicio del XX, Noel obtiene unas conclusiones demoledoras: ese calificativo es escarnio de la época en que se ideó, afirma, pues los españoles desengañados de la política han traspasado su pasión a una figura tan antigua como el torero, pero idealizándolo con la atribución de nuevas cualidades.

En «El bohemio» Emilio Carrere idealiza y elogia el mismo concepto de la bohemia, y el espíritu independiente del bohemio como su rasgo identificativo. Lo contrapone al empleado probo y al covachuelista, término este que el propio N. Anaya, autor del artículo «El covachuelista» en la colección Los españoles pintados por sí mismos ya consideraba antiguo en 1843, pues había sido sustituido por «oficial de secretaría». La vestimenta también separa al más moderno de los tipos del más atrasado y vetusto, y el sombrero se convierte en emblema de esta oposición: los cómodos «sombreros de alas anchas y flotantes» contrastan con los «odiosos bombines, abominables hongos», emblema de la vulgaridad, como lo es la chistera, que inspira en Carrere greguerías como las había inspirado en Gómez de la Serna, y mucho antes en Pérez Galdós: «La anacrónica chistera es la vanidad; la chistera cubre brillantemente la oquedad mental. Es modesta, petulante como un artículo de fondo y estúpida como un reporter de salones», afirma Carrere. Y sobre todo, el ejemplo más cercano de bohemio que destaca y ensalza es el de Alejandro Sawa, a quien califica como "emperador de la bohemia». Como se trata de sublimar lo que es el verdadero bohemio, conviene clasificar y distinguir con claridad a estos tipos, y para ello avisa Carrere sobre cómo deslindar los conceptos de bohemia y hampa. El cierre del artículo eleva al bohemio como un poeta opuesto al ambiente mediocre, un romántico preocupado únicamente por la belleza, la literatura, la poesía y su propia independencia. Como ha 
visto Jesús Rubio, la colección, que profundiza en el arte de la caricatura que ya se apuntaba en la colección original decimonónica, conecta algunos de sus tipos bohemios e intelectuales con los que presenta Valle en Luces de bohemia. (2006, pp. 64-70).

2. En cuanto al recurso a las autoridades que se han ocupado anteriormente del tipo, vemos cómo en «El fenómeno», Noel se vale de citas de pensadores extranjeros como «autoridades», para interpretar las causas del asombroso hecho de que un pueblo descontento y sufriente se vuelque, como en catarsis, en un espectáculo sangriento en la plaza de toros.

Por su parte, Antonio Zozaya pretende fijar en «El cochero de punto» un tipo de amplia tradición, pero próximo a extinguirse ante la aparición del moderno chauffeur que maneja los vehículos mecánicos fruto de la modernidad. Para ello sigue la usanza de apelar a las autoridades que antes que él trataron el asunto (implícitamente se evoca el artículo «La diligencia» de Larra), recuerda la gran información que dio Fernández de los Ríos sobre el cochero a través de los siglos y aduce citas varias con cierto prurito de erudición. Por ejemplo, recuerda cómo Saint-Évremond vilipendiaba a los cocheros de alquiler, mientras que dos siglos después Taine los ensalzaba. El artículo de Zozaya vendría a insertarse en la serie de hasta tres artículos de tema semejante aparecidos en Los españoles pintados por sí mismos del siglo anterior: «El cochero», de Cipriano Arias, «El calesero», de Juan Martínez Villergas, y «El mayoral de diligencia» de Antonio Auset, pero sin alcanzar la gracia y el humor del segundo, escrito en verso polimétrico, ni la información técnica sobre los tipos del transporte y las anécdotas costumbristas de Arias y de Auset.

En «La modistilla» el escritor, traductor y crítico literario González Blanco, de claros gustos privados por el Madrid castizo ${ }^{5}$, recurre como autoridades a dos expertos conocedores de la vida madrileña, Pedro de Répide y Diego de San José, a los que atribuye el haber estudiado el «alma antigua» de Madrid. La modistilla alegre y coqueta formaría parte del alma actual de Madrid, según el autor, y su modernización consiste en haber adoptado un aire parisino que quita rigidez a la vida de la ciudad y transmite por la capital «el alma de París»

5. Según semblanza de un contemporáneo, el prolífico Andresín compensaba con su aparente vida privada frívola y ligera su pedantería de "sabihondo critico», y así «va a las verbenas y tiene relaciones efímeras con modistillas y heteras sentimentales», al igual que el matemático y teósofo Francisco Vera, gran amigo de Blanco, «sostenía relaciones con una modistilla que conoció en una verbena» (Cansinos Assens, 1985, pp. 34-36). 
mediante los perfumes, las joyas, los trajes y los comportamientos amorosos bastante libres.

Serafín y Joaquín Álvarez Quintero presentan en «La estrella del género ínfimo» un tipo contemporáneo en un formato que califican de «un ligero estudio, entre psicológico y de costumbres» de la nueva figura artística. Pese a la novedad, se obligan a seguir la retórica del artículo de costumbres decimonónico en cuanto a definir el concepto y proponer autoridades, antecedentes y evolución del tipo. A ello se aplican los autores, al invocar a antiguas y famosas cantaoras y bailaoras, para insertar en su serie a las actuales, a las que también nombran.

3. Por lo que respecta a la tradición costumbrista de explicar el origen y la evolución histórica del tipo, Antonio Hoyos y Vinent, pese a la modernidad del tipo de «La deportista», sigue la tradición del recorrido histórico y el trazado de la evolución: ese recorrido ha de ser aquí por fuerza breve, ya que para Hoyos las únicas mujeres deportistas españolas habrían sido las damas cazadoras inmortalizadas por la pintura, o la dama con atavío de cazadora hallada por el Caballero de los Leones en El Quijote.

Joaquín Dicenta declara en su artículo la imposibilidad de encontrar rasgos específicos del albañil español, y como al parecer sí había algún rasgo distintivo tres décadas atrás, al menos en cuanto a los albañiles madrileños, resuelve comparar a aquellos con los del presente.

El tipo de la modistilla se pone en conexión con la antigua «manola desgarrada e impulsiva que mataba por celos». La relación amorosa de las modistillas con los estudiantes forma parte central del artículo así titulado, que resulta más bien un esquema del costumbrismo trasnochado y libresco del autor que cuatro años antes había editado la novela Matilde Rey, a la que alude en este artículo como «novela de costumbres madrileñas y de estudiantes provincianos». Por más que González Blanco subraye una y otra vez vocablos ingleses y franceses para acreditar la modernización operada en los usos de la modistilla, en verdad el tratamiento del tipo resulta ser un híbrido entre la chula madrileña, la antigua maja y la coqueta. No falta en el texto la tradición de las comparaciones plásticas, al igual que en otros autores de la serie, que asociaban la pervivencia de ciertos tipos madrileños con cuadros de Goya. En esta ocasión, la modistilla sería a la vez una pintura de Goya y de Felicien Rops, según el autor.

4. Si pasamos al seguimiento de la tradición de las clasificaciones y subclasificaciones del tipo y sus variedades, un caso evidente es el de «El bohemio»: además del que lo es por «independencia espiritual», Carrere destaca el 
bohemio pintoresco, el tabernario y el lúgubre, variedades que ilustra con ejemplos antiguos y contemporáneos: de los tabernarios, algunos coetáneos que imitan a esos «ilustres borrachos que se llamaron Poe, Verlaine, Baudelaire, que fueron grandes no por el alcohol, sino a pesar del alcohol».

En «La estrella del género ínfimo» encontramos la clasificación o repertorio de las modalidades del tipo, aunque encomendada a la transmisión en estilo indirecto libre de los relatos de la artista y a su conocimiento del medio musical del «género ínfimo».

Luis Bello, quien no refleja una profesión, ni afición, ni ámbito social, sino un comportamiento transversal a cualquier sector español en «El hombre que hubiera servido mejor para otra cosa», publicado el 26 de agosto, comienza adoptando el «deber clasificatorio» que considera propio del costumbrismo, pero creando la expectación del lector en forma de adivinanza:

¿Es español? Sí: es un buen compatriota. Todos los tipos humanos tienen en España su color y su sabor. Españolísimo es. La primera observación que ha de hacerse, si queremos clasificar con algún acierto, nos obliga a llevarle al terreno adecuado. ¿Dónde? Al lugar en que trabaja.

Empeñado burlonamente en la consuetudinaria clasificación del tipo, advierte Bello la gran dificultad de la tarea, máxime cuando existe además otro pariente muy español, cuyas manifestaciones son parecidas: «el maltrabaja», el vago que no trabaja porque no quiere, del que el otro, el que hace mal su trabajo porque no es adecuado para él, debe deslindarse.

La terminología al uso del siglo XIX en cuanto a subdivisiones y especies sirve también en «El golfo» para enmarcar al golfo madrileño «como tipo representativo de la especie», cuyos antecedentes fueron el manolo, el chispero y el chulo, origen que Pedro de Répide acredita con autoridades y datos. De las variedades madrileñas, cuenta con detalle y compasión la vida de los miserables, y los lugares y calles de Madrid donde habitan, así como la vida de los hijos de clases medias, dados a los bailes públicos. Se demora en esta variedad, lo que le permite verter la mucha información de que dispone sobre calles, establecimientos, etc., como uno de los mejores conocedores de la historia y geografía urbana de Madrid que era ya en 1915.

En «El sepulturero», Gabriel Miró es consciente de los antiguos usos del artículo de costumbres, y de que la tipificación requiere el singular, como así lo reconoce en el texto. En otro comentario metaliterario acepta implícitamente la retórica de las clasificaciones y genealogías, para aclarar que en su tipo «No hay categorías de fosadores o sepultureros, sino linajes». En cuanto a la descripción física e indumentaria, advierte el autor que tampoco es posible la caracterización específica, ya que el sepulturero parece terrible solo por 
el contexto, pero en otro lugar y con otra vestimenta se confundiría con un albañil o un empleado cualquiera.

Rafael López de Haro deja igualmente constancia en «El notario» de su fidelidad a la moda clasificatoria que organizaba tantos artículos de la colección del siglo XIX, y así distingue tres tipos de notarios, «los notarios notarios, los notarios neurasténicos y los notarios pensadores», de entre los cuales, el último modelo, el más útil a la nación, se ilustra con el caso concreto de Joaquín Costa. A su vez los notarios rurales aparecen como subgénero de la fauna oficial cuya embriología señala con típicas metáforas científicas del costumbrismo decimonónico. Y además, en el artículo se imitan los rasgos formales del género en cuanto al seguimiento del tipo con la familiar denominación «nuestro hombre», y en cuanto al resumen de una biografía profesional prototípica.

5. Por lo que afecta al trazado biográfico y temporal de la vida del tipo, «El viajante catalán» de Rusiñol es fiel en parte a la estructura clásica del seguimiento durante un día de la vida del tipo, mientras que el recorrido por toda la vida del tipo se encuentra en aportaciones de la colección como «El poeta de juegos florales», publicado por Enrique Díaz Canedo el 16 de septiembre, donde se recorre toda la vida del poeta. En «El golfo» Répide sigue la tradición de trazar la biografía del tipo hasta el final, al apuntar que el golfo en su vejez no es tal, sino un hombre útil como ciudadano y familiar, en el caso de que no acabe enfermo. «El cochero de punto» concluye con el final trágico de la vida del tipo, cuyo entierro compone una vistosa escena plástica que, puede suponer el lector, pronto será una estampa antigua con la extensión de los nuevos vehículos de motor.

\section{El regeneracionismo en la serie costumbrista}

Los usos figurados del léxico científico y organicista

Es indudable que este tipo de léxico figurado era muy frecuente en los artículos de la colección del siglo XIX, hasta convertirse en uno de los rasgos de la retórica del género. Pero su presencia en Los españoles pintados por sí mismos de la revista España responde no sólo al seguimiento de los estilemas de la colección homónima, sino al designio crítico con que el Regeneracionismo utilizó y desarrolló esos usos figurados. En «El opositor», José de la Serna entronca a su tipo con el pedante don Hermógenes de Moratín mediante una cita de este, tras lo cual incluye terminología científica en usos figurados, en fórmulas como «individuos de su especie» o «ascendencia». Concurre también el recuerdo del artículo «La planta nueva o el faccioso» de Larra, caso famoso y ejemplar de alegoría científico-botánica: «Acaso Larra la llamaría [a 
esta nueva profesión] una nueva planta, que brota en todas las floras universitarias y retoña en la villa y corte $[\ldots] »$

Manuel Bueno abre «El periodista» reflexionando sobre el lugar que ocuparía el tipo «en la zoología literaria» (p. 5). No faltan alusiones a Linneo y Huxley al tratar de un tronco familiar común entre el periodista y el literato, ya que el periodista es visto como la «fosilización y domesticación» de quien comenzó como literato.

En «El señorito chulo» es generalizadora la parte que lleva el título de «El señorito», que sería el tipo general del que se desgaja el que da nombre al artículo. El especimen andaluz que representaría la variedad del «señorito chulo» es comparado con el madrileño, por medio de la terminología científica que proviene tanto del costumbrismo romántico como del determinismo científico del Naturalismo y el más cercano organicismo expresivo del Regeneracionismo: gusanos, leyes de la embriología que «se cumplen en los individuos como en los países», metamorfología, influjo del medio... Mediante esta vía expresiva, Eugenio Noel concluye que el estadio final de la evolución de la especie del tipo tratado es el cacique, figura central en los diagnósticos regeneracionistas sobre los males de la patria, a partir del pensamiento de Joaquín Costa.

En el artículo «El fenómeno», Noel hace que una parte de la estructura del texto imite también la terminología científica propia del costumbrismo del XIX, pasada ya por la formulación regeneracionista de las enfermedades del organismo nacional. Muy expresivo del intento de localizar las causas y desarrollo del mal es el epígrafe titulado «SU INCUBACIÓN», que comparte usos figurados médicos con los pensadores regeneracionistas, como los que recorren Los males de la patria (1890) cuando, por ejemplo, el mal del caciquismo rural era calificado por el pensador de «tremenda plaga», advirtiendo además cómo «la nación se halla demasiado débil» para desprenderse de esta «hidra» que la oprime y que «toda la sangre ha enviciado» (Lucas Mallada, 1990, pp. 187188). Esta terminología alcanzó no sólo a la eventual elocución, sino hasta la estructura del libro El problema nacional (1899), donde Macías Picavea, sobre todo en los capítulos «Las causas» [del mal] y «Remedios», organiza epígrafes («Parálisis de la evolución y germanismo», «Defensa orgánica y transmisión del mal», entre otros) en los que muestra su concepción organicista del país. (Macías Picavea, 1992, pp. 217-229)

La crítica de los males nacionales: el golfo, el señorito ocioso, el vicio taurino Los artículos regeneracionistas sobre el mal del señoritismo, o sobre la golfería nacional que trató Pío Baroja bajo la firma «el Doctor Baroja» en su artículo 
«Patología del golfo» publicado en 1899 en Vida Nueva, tienen su continuación en algunos de los tipos retratados en la nueva serie del semanario España.

Ambos problemas, el de la golfería nacional y el de las diversas modalidades de señoritos inútiles, aparecían también en otras secciones de la revista. En «El golfo», Pedro de Répide busca los antecedentes del tipo, y relaciona el concepto de «golfo» con el de «señorito», tipo este eterno y universal aunque de origen muy español.

El tipo del señorito aparece en ciertas variantes: la urbana, las rurales andaluza y catalana. El señorito urbano y cosmopolita es presentado por C. Rivas Cheriff en «Un muchacho bien» como un tipo contemporáneo caracterizado de forma absolutamente negativa, a partir de su ideología, por completo opuesta a la línea editorial que sostiene la revista España: el joven, con expectativa de acta de diputado, se declara «germanófilo convencido». Se trata de un esnob despreocupado pero culto e ingenioso, capaz de jugar con vocablos en inglés y francés y citar en alemán. Argumenta festivamente contra la ideología de izquierda, y explica al receptor de su carta todos sus gustos y actividades, con lo que tenemos así un completo repertorio de las filias y fobias políticas, literarias, periodísticas, etc., de este señorito bien, que incluso hace una alusión burlona al periódico España y a «la literatura de esa que escribe la gente seria de ESPAÑA».

«El hereu» de Joaquin Montaner, pinta la vida de un señorito rural catalán altivo y ocioso, que despilfarra en ferias y juegos el patrimonio logrado por su padre con mucho trabajo. El joven, ante la impotencia de su padre y hermanos menores, hace valer sus derechos de hereu sin reconocer deberes. Obtiene todo lo que desea de la casa familiar, y pasa su vida montando en su jaca y tartana y buscando la diversión permanente.

La versión andaluza aparece en «El señorito chulo» de Eugenio Noel, tipo que queda presentado primero por su palabra. Con un diminutivo ridículo y ya significativo, Bibi, de 30 años, es el hijo consentido de una madre malagueña y del cacique de una ciudad, latifundista, jefe de un partido político, que no duda en comprar a la justicia si es preciso para ocultar los desmanes de su vástago. El autor insiste en que se trata de un prototipo o modelo de una vida muy común en Andalucía, organizada sobre los toros, la jarana, las reuniones entre afines en el llamado casino de señores, y la falsa igualación social en la asistencia al colmado y a las peleas de gallos. Son constantes los vituperios que Noel lanza sobre este espectáculo que cree envilecedor, y cuyos protagonistas, los gallos, son igualados metafóricamente con los señoritos que concurren como espectadores. 
En este extenso y variado artículo, el más amplio de los veintidós que componen la serie, confluyen rasgos de ensayo moral regeneracionista, en su denuncia tanto de un ambiente consentidor que lo genera y fomenta, como del propio tipo del señorito "producto de una inmensa degeneración», que aprovecha las grietas del Estado y de la justicia para vivir fuera de toda norma social. Tanto el Bibi que ha servido de ejemplo, como su amigo el marqués, son variedades complementarias del tipo del «señorito indecente». Describe Noel plásticamente, como si hiciese la écfrasis de un grabado, la estampa de ambos a caballo, a uso de bandidos o contrabandistas. Y lo hace para emitir una implacable descalificación y el aviso sobre un peligro: la pervivencia de las tradiciones de iconografía pintoresca que provienen del romanticismo y de ciertos relatos idealizantes de la vida andaluza transmitidos por escritores románticos y, posteriormente, por autores casticistas.

Finalmente, la denominación de «calaveras» que aplica también al tipo, apunta a una especie deleznable persistente a través de los siglos: los calaveras a los que Larra dedicó dos artículos en junio de 1835 están lejos de desaparecer de la escena nacional a las alturas de 1915, para desesperación de los promotores de una nueva España regenerada.

Debió de causar gran impacto este artículo, a juzgar por el orgullo que su autor declara en una inusual nota al pie contenida en su siguiente artículo, «El fenómeno», que dice así: «Nuestro humilde artículo anterior, "El señorito chulo", ha tenido fortuna. Muchos periódicos de provincia lo han copiado; hemos recibido cartas de felicitación, inspiramos con él artículos de fondo $[\ldots] »$.

Por otra parte, los pensadores regeneracionistas, y posteriormente la intelectualidad novecentista, compartieron la beligerancia contra la afición taurina en cualquiera de sus manifestaciones, por su brutalidad y por su asociación con los males del señoritismo y la golfería. Es frecuentísimo en este ambiente encontrar afirmaciones como la de Giménez Valdivieso, quien en 1909 señalaba la necesidad de «que los españoles amantes de su país se unan para extirpar las fiestas bárbaras», entre las que incluye las capeas de los pueblos y las corridas de toros, a las que califica como «espectáculo que repugna a todo espíritu delicado». (Giménez Valdivieso, 1989, pp. 214-215)

La afición taurina parece formar parte sustancial de las pasiones del señorito español de la época, y resulta tratada con dureza en diversos artículos de la colección, en el contexto de la posición explícitamente anti-taurina que suele sostenerse en las páginas de España. Así, en el n. ${ }^{\circ} 20$ de 11 de junio, p. 4, uno de los apartados de la sección «Panorama grotesco», titulado «El señorito», censuraba inveteradas costumbres de «el señorito profesional de 
los toros, el café y el piropo». En la sección «La vida real de España», el primer artículo breve de 2 de diciembre, «La afición...y lo otro», versaba sobre la controversia generada por el nuevo impuesto con que se iban a gravar las corridas. Los aficionados son allí objeto de unas críticas que los ubican en la España vieja y atrasada, sobre todo en una estereotipada Andalucía, a la que el semanario hace frente: "esto [el gravamen] como otras veces, ha puesto enfrente a la Sevilla de pandereta y a la otra Sevilla que trabaja y es culta, moderna y progresista», se dice expresamente. Un artículo muy significativo dentro de la revista España en 1915 es también «El club Guerrita», de Santiago Rusiñol, publicado el 2 de abril, p. 2, en el que el autor dibuja a los «devotos» del idolatrado torero Guerrita, todos iguales, «gente de sombrero ancho, de pantalón estrecho, de soguilla», el trato reverencioso que dispensan a su ídolo y sus absurdas conversaciones en un estilo directo de lacónicas frases en andaluz, que redondea la presentación esperpéntica de la pasión taurina. Por lo que respecta a obras de ficción coetáneas, Hoyos y Vinent había publicado cuatro novelitas sobre el ambiente taurino en 1914, que denuncian el aplebeyamiento andalucista de la clase alta, al presentarse en ellas un mundo en el que alternan aristócratas ociosos con toreros que en su mayoría proceden de los estratos más pobres, y que les sirven de capricho y entretenimiento, en una reedición del fenómeno del majismo contra el que tan críticos fueron autores ilustrados como Jovellanos, por ejemplo en sus dos «Sátiras a Arnesto». En una de estas novelas, La estocada de la tarde, Hoyos recrea el ambiente taurino de un veraneo en San Sebastián, y la relación de una caprichosa marquesa con un torero andaluz de origen muy humilde, prototipo de tantos como se habían lanzado a esa profesión no por arte, sino por el hambre. En Los héroes de la visera, el torero es perseguido por una mujer mundana enriquecida que insiste en ser su amante. En ambas, el desengaño final de los toreros conlleva una moraleja: la toma de conciencia del imposible ascenso social y de ser juguetes del ocio y del capricho ajeno.

Un caso semejante lo encontramos en Eugenio Noel. De los nueve relatos que componen el libro Nervios de la Raza, los cuatro primeros tratan directamente el mundo de las capeas y el toreo en el mundo rural: «Un toro de cabeza en Alcorcón», «Cura trágica de un maletilla», «Los caballistas de Arroyo del Puerco» y «Capea jocosa en Segurilla».

La pasión taurina caracteriza a todos los señoritos que aparecen en los artículos de Los españoles pintados por sí mismos, y además forma parte de numerosas conversaciones sostenidas por otros tipos en los artículos. Es idéntica la visión del mundo taurino que, un año después de las mencionadas novelas de Hoyos y Vinent, proponen algunos de los artículos de Los españoles 
pintados por sí mismos en 1915, como si los artículos de costumbres fuesen un esquema de los personajes y escenas que contienen tanto las citadas novelas de Hoyos como las narraciones coetáneas de Eugenio Noel.

El persistente antitaurino que fue Eugenio Noel entregó el artículo «El fenómeno» actualizando críticamente una de las modalidades del tipo de «El torero» con que Tomás Rodríguez Rubí abría la colección costumbrista de 1843. El «fenómeno» de Noel, tiene relación con «el torero bravucón» de Rubí: el ser andaluz le asegura «ser reputado desde luego como apto y conveniente para el oficio», acompaña a nobles y aristócratas en las capeas, etc. (Los españoles pintados por sí mismos, 1851, p. 3).

En la misma revista España, Noel había publicado en el n. ${ }^{\circ} 31$ del 26 de agosto su durísimo artículo de opinión «Datos del flamenquismo», y el 8 de noviembre, el primero de los dos artículos que aportó a Los españoles pintados por sí mismos, «El señorito chulo», que acabaría Noel rehaciendo y ampliando para formar una de las partes de su libro Señoritos, chulos, fenómenos, gitanos y flamencos. (Eugenio Noel, 1916, pp. 17-102). La pasión por «el fenómeno» estaba actuando como sustituta espúrea del interés genuino que todo ciudadano debería tener por la vida política que tanto le incumbe, y sería prueba del despego y del desprecio por los políticos. A cambio, «el fenómeno» procede de la clase baja y se juega la vida desde adolescente. La relación entre política y toreo va siendo desgranada por Noel desde diversos puntos de vista, uno de ellos el de las analogías lingüísticas, plasmadas en las muy agudas observaciones de tipo léxico que proporciona el escritor:

El lenguaje usado en las gradas del circo se enriqueció con términos parlamentarios o modalidades periodísticas, saltó luego al arroyo, se encenagó con el barro sucio de los modismos, de la vida pobre y se repartió en las hojas del Diccionario, en las papeletas de los académicos [...] Las crisis políticas en número pavoroso arrojaban centenares de desilusionados a las piedras de los tendidos

Al igual que había expresado respecto al tipo del señorito, le preocupa la frecuente aparición de la tauromaquia en el arte y hasta en la publicidad, y el gran número de libros de éxito sobre el arte del toreo que proliferaban.

\section{Costumbrismo, designio crítico y propuestas renovadoras}

La estirpe regeneracionista de algunos artículos presenta un llamativo contraste con otros muy conservadores en contenido y estilo. Manuel Bueno destaca entre los primeros con su tipo «El periodista», que se va orientando hacia un ensayo de opinión sobre cómo los españoles han dejado de ser críticos y de actuar contra sus gobernantes, al igual que han ido haciendo los 
periodistas. Bueno, periodista él mismo, realiza una fuerte crítica sobre cómo el periodista, voluntaria o involuntariamente, se ha ido haciendo cómplice de lo que denomina la «farsa»y «humillante comedia nacional» en que se ha convertido la vida política. Él mismo se incluye en un plural que debe asumir la responsabilidad de reconocer cómo los periodistas han ido «renunciando a la crítica honrada» y cómo justamente han dejado de ser un referente para merecer, al igual que los oradores, el descrédito de parte del público.

De índole moral e intención reformista es el tipo que traza Luis Bello, «El hombre que hubiera servido mejor para otra cosa», publicado el 26 de agosto, que no refleja una profesión, ni afición, ni ámbito social, sino un comportamiento transversal a cualquier sector español. Se trata del único tipo caracterizable por desempeñar mal su trabajo, sea este el que sea, y por ello resulta frecuentísimo, llegando a incluir a «el ministro, el obrero, el coronel o el mozo de café», según palabras de Bello, o incluso a grandes políticos como D. Francisco Silvela, que «descubrió a última hora, cansado del gobierno, que él no servía para gobernar a España».

La propuesta final de Bello es la necesidad de orientar bien a cada cual según sus capacidades, para que no se siga dando el caso de tantos jóvenes que hubieran sido más útiles y felices trabajando en sus pueblos, en vez de abandonar sus lugares por la manía de todo rico rural de mandar al varón a estudiar Derecho a la capital. No es extraño que se sirva como «autoridades», de Unamuno, al asumir sus reflexiones sobre las peculiaridades de la España ibera y la España mora, y del regeneracionista Joaquín Costa, con el que concuerda en la necesidad de evitar el absentismo rural y de prestigiar la vida en campos y pueblos.

\section{La representación del mundo obrero}

El caso más emblemático lo representa Joaquín Dicenta con su aportación, «El albañil», continuación de su interés por el mundo obrero que ya había plasmado en su famoso drama Juan José, estrenado en 1895, donde ya aparecía el mismo tipo que retoma veinte años más tarde para la colección costumbrista. En Alma Española quedó igualmente la huella de su denuncia de la explotación del obrero y de la precariedad económica de las familias, en dos artículos de 1903. «En el fondo de la mina. Almadén», el 8 de noviembre, pp. 4-7, hacía valer su calidad de testigo para denunciar las condiciones espantosas de la mina a la que había bajado, así como la explotación del estado español hacia el minero, más inicua aún que la de las empresas particulares. En «Dinero», el 29 de noviembre, pp. 4-5, lanzaba un durísimo alegato contra los préstamos usurarios y las casas de empeño que devoraban a las familias 
humildes. Su yo vehemente de testigo y sus impulsos casi vengadores se revelaban también en este artículo.

En «El albañil» Dicenta parece evocar el antiguo albañil brutal, bebedor y jugador el día de cobro, requebrador de mujeres, con gesto y actitudes que lo asemejaban al pícaro. A pesar de tales rasgos, Dicenta se preocupa por deslindar el albañil real del tipo de el chulo reflejado por el teatro menor de los sainetes. No es esta la ocasión de trazar el recorrido literario del tipo, que aparecía ya en Gaspar Zavala y Zamora, o en el sainete de Ramón de la Cruz El albañil malcasado, pero Dicenta rebate que los albañiles reales se expresen «como les hacen hablar ciertos autores cómicos y ciertos poetas populares», expresiones más propias del tipo del chulo, del cual debe deslindarse claramente el albañil. Buena parte del artículo de Dicenta se dedica al recuerdo de antiguos modelos de albañil, y finalmente apunta al contemporáneo, más respetuoso de su familia, y con conciencia de clase.

Otro de los tipos que corresponden al mundo del trabajo más duro es «El marinero de cabotaje», publicado por Francisco Acebal el 19 de agosto. El autor manifiesta explícitamente sus dudas sobre si existen o no unos rasgos españoles del marinero que vive enrolado a una tripulación de cabotaje. Como en el caso de Dicenta, que «reaprovecha» su tipo del Juan José, podemos suponer que el éxito que el asturiano obtuvo quince años antes con su novelita Aires de mar le impulsaría a optar por este tipo, y por la descripción de las labores en los barcos denominados pataches, reconociendo expresamente que se trata de una embarcación y de una forma de vida en extinción. López Acebal demuestra su conocimiento de la terminología de las embarcaciones y las costumbres marineras y, al modo de los novelistas del realismo del siglo XIX, declara su previa documentación y estudio del natural, y sus muchas horas en los fondeaderos, observando las faenas marineras, hablando con los trabajadores y hasta trabando amistad con algunos de ellos. Su autoridad de testigo le permite reflejar de forma realista y objetiva las duras vidas de los marineros desde que son adolescentes. Pero en su condición de espectador asiduo del ambiente marinero, puede reflejar también la belleza de ciertas noches en el puerto o de una escena en la que un marinero toca el acordeón.

\section{La vieja España y la moderna España: la vanguardia modernista frente a} la antigua poesía. Los modernos sports frente al casticismo secular

Dos artículos, «El poeta de juegos florales» $\mathrm{y}$ «La deportista», nos servirán finalmente para ilustrar el cambio de época del que la colección deja claro testimonio desde la óptica costumbrista. En el primero, Díez Canedo creó un risible figurón, una caricatura, a partir de un tipo y un ambiente que conocía 
bien, después de haber editado él mismo varios libros de poesía. Desde el principio, el autor se vale de abundante estilo indirecto libre que representa los pensamientos y las dudas de un maduro poeta a la antigua usanza, asiduo de los certámenes y juegos florales de toda España en los que ya ha obtenido algunos premios, alguno tan ridículo como la pomposa corona de laurel con cintas que decora su despacho. Su hábitat doméstico, en particular el despacho, se refleja con detalle para desenmascarar el modo de ser y costumbres privadas del tipo, fuera de su exhibición social.

Esta variedad de poeta se desgaja del tipo general del poeta que había aparecido ya en Los españoles pintados por sí mismos como aportación de Zorrilla, y en la contemporaneidad de Díez Canedo se presenta como un funcionario solterón que comparte con su viuda hermana y su sobrina una vida rutinaria y ordenada, sin el menor atisbo de inspiración ni vocación poética. A través de sus recuerdos, resumidos en estilo indirecto, se nos hace testigos de las escenas de juegos florales provincianos, con su pesado mantenedor, el engalanado público y las imprescindibles reina y damas, que a veces bostezan escuchando al poeta. Como el tipo del erudito de Andrenio, también este improductivo personaje vive fuera de su tiempo y de los afanes regeneracionistas de los intelectuales, como lo prueba su enfado cuando los mantenedores hablan cada vez más de «los males de España». Las citas textuales de uno de los pretenciosos poemas dedicado al pie forzado del certamen, contribuyen a la ridiculización del anacrónico tipo, antigualla viviente que, aunque reside en la capital, se presta a formar parte de un mundo provinciano de fuerzas vivas locales, que sigue manteniendo la tradición de los juegos florales. Todo ello se opone a unas nuevas actitudes y estéticas, las de los jóvenes poetas modernistas, que aparecen vistos desde la perspectiva del poeta de juegos florales: «Ya deben saberlo los dos o tres poetillas modernistas que se sientan en el Suizo, con sus melenas, sus sombreros blandos y sus corbatas deshechas, porque al verle pasar, todos han coreado con risas la frase de uno de ellos».

El autor no incluye glosas ridiculizadoras, pues son las palabras directas de los personajes las que descubren la posición atrasada de los individuos. Por ejemplo, es la opinión del canónigo sobre los poetas modernistas la que cierra el artículo: «Desengáñese -dice el clérigo- ya no hay apenas poesía. Estos escritorcitos de ahora no tienen imaginación, ni sentimiento, ni fe... Lo que escriben, ni siquiera son versos...»

La dialéctica entre la vieja España y la nueva, omnipresente en el semanario, tiene su manifestación en este artículo en el contraste entre dos estéticas 
muy diversas en la poesía, y todo lo que conllevan en cuanto a su exposición social y el ambiente en que se difunden.

El enfrentamiento entre generaciones literarias aparece también en una breve pero curiosa digresión en la que Sánchez Blanco, autor de «La modistilla», se declara de «la generación siguiente» a Azorín y Baroja, a los que contradice como al desgaire en su defensa de unos versos de Campoamor. Sin embargo, esta declaración de modernidad novecentista no se corresponde ni con el tipo elegido, ni con el tratamiento del mismo, ni con la defensa de Campoamor, cuyo estudio biográfico y literario había editado Sánchez Blanco solo tres años atrás, pese a estar Campoamor muy alejado ya de los gustos de los más modernos. El artículo que aporta a la serie de Los españoles pintados por sí mismos resulta también algo anacrónico, y de un sabor rancio muy ajeno al empeño de hombres y mujeres de la Generación del 14 en modernizar la vida de la mujer española.

«La deportista» de Antonio Hoyos y Vinent introduce un nuevo tipo, del que a priori sería imposible reconocer tradición alguna, por ser uno de los iconos de la modernidad en España, y más aún en su tipificación femenina. Tal vez el origen aristocrático, la vida cosmopolita de Hoyos y su propio interés por el deporte (fundó y dirigió la revista Gran Mundo y Sport que se mantuvo durante 1906 y 1907) le hicieron optar por este tipo contemporáneo, que evidentemente se daba solo en las altas esferas.

$\mathrm{Al}$ autor le interesa anotar las diferencias que adopta este tipo en Inglaterra, Italia, Francia; y en España, donde llevaría desventaja a causa de las costumbres de presunción y molicie de las damas españolas, tan contrarias a la práctica del deporte.

En su apartado tercero y último, el artículo se dedica a los espacios de prácticas del sport en Madrid, también copiados del extranjero: un insólito chalet de arquitectura suiza y aires cosmopolitas, donde las damas elegantes toman el té y las jovencitas «flacas y pálidas, vestidas con cortísimas y amplias sayas blancas, persiguen las bolas del golf o pegan grandes brincos jugando al tennis».

Lejos del entusiasmo de la inminente vanguardia ultraísta por los sports como icono de la modernidad, y a los que convertirían en objeto de poemas y narraciones, Hoyos muestra su escepticismo crítico: este ambiente moderno no es para él más que una pátina superpuesta al permanente casticismo español: muy cerca de ese islote de los sports se agazapa el ambiente castizo español, las fiestas y verbenas en la Moncloa, las lavanderas tendiendo las ropas en el río, los organillos amenizando los merenderos, y los alegres niños desharrapados zambulléndose en el agua. Las comparaciones plásticas tan 
usuales en el costumbrismo decimonónico no faltan aquí, y el artículo contiene emblemas iconográficos del contraste entre la modernidad cosmopolita y el casticismo madrileño secular, invencible: «Y es Goya que triunfa, que pone irónico el fondo de sus tapices al exotismo de los elegantes».

Tal vez el espíritu de la serie a la que acabamos de aproximarnos se encuentre más cerca de la colección Los españoles de ogaño, de la que Rubio y Ayala destacaban «el pesimismo y un cierto humor o ironía» y «la visión crítica de la sociedad española» (Rubio Cremades y Ayala, 1985, pp. 70-71) que de la homónima del s. XIX cuyos modelos invocaban sus editores. Pero a pesar del desigual interés y calidad de los artículos, el conjunto de estos escritores dejó huella en sus textos de las tensiones de una época de cambios esenciales en la vida y la literatura españolas. Por un lado, el apego a tiempos, tradiciones y modos expresivos antiguos, que el pie forzado de la colección del siglo XIX animaba a seguir, en cuanto a la selección de los tipos y a los estilemas o la preceptiva del cuadro de costumbres propios de los artículos del siglo anterior. Por otro, la necesidad de experimentación formal sobre el molde del género. También, el deseo de reflejar una nueva época que lograse identificar y extinguir, en la vida y en la literatura, la evolución de algunos tipos antiguos que resultaban insanos para todos aquellos que compartían la idea de España que propuso incansable la revista homónima.

\section{Bibliografía citada}

Alma española, edición facsimilar, Madrid, Ediciones Turner, 1978.

España. Semanario de la vida nacional, edición facsimilar, Liechtenstein, Topos Verlag/Turner, 1982.

Los Españoles Pintados por sí mismos [1843-1844], Madrid, Gaspar y Roig Editores, 1851.

Baroja, Pío, «Patología del golfo», en Revista Nueva, 1899, ed. facsimilar con estudio preliminar de José Carlos Mainer, Barcelona, Puvill Editor, 1979, Vol. I, pp. 145-154.

CANSINOS AsSEnS, Rafael, «Andrés González-Blanco y sus amigos», en La novela de un literato, vol., 2, edición preparada por Rafael Cansinos-Asséns, Madrid, Alianza Editorial, 1985, pp. 34-43.

GimÉnez VAldivieso, Tomás, El atraso de España, Madrid, Fundación Banco Exterior, col. Biblioteca Regeneracionista, 1989.

GonzÁlez Blanco, Andrés, Matilde Rey (Novela de chulas madrileñas y de estudiantes provincianos), Madrid, Renacimiento, 1911.

Hoyos y Vinent, Antonio, Oro, seda, sangre y sol. (Las novelas del toreo), Madrid, Renacimiento, 1914. 
Macías PICAVEA, Ricardo, Los males de la patria, Madrid, Fundación Banco Exterior, col. Biblioteca Regeneracionista, 1992.

MALlADA, Lucas, Los males de la patria y la futura revolución española, Madrid, Fundación Banco Exterior, col. Biblioteca Regeneracionista, 1990.

Noel, Eugenio, Nervios de la Raza, Madrid, Renacimiento, 1915.

- Señoritos chulos, fenómenos, gitanos y flamencos, Madrid, Renacimiento, 1916. ROMÁN Román, Isabel, «Galdós y el regeneracionismo», en AA.VV., Actas del VI Congreso Internacional de Estudios Galdosianos, Las Palmas, Ed. del Cabildo Insular de Gran Canaria, 2000, pp. 100-114.

Rubio Cremades, Enrique, y M. ${ }^{a}$ Ángeles Ayala, Antología costumbrista, Barcelona, El Albir, 1985.

RUBio JiMÉNEZ, Jesús, Valle Inclán, caricaturista moderno. Nueva lectura de Luces de bohemia, Madrid, Fundamentos, 2006.

Fecha de recepción: 11/04/2014

Fecha de aceptación: 30/09/2014 